\title{
Rapid stabilization of municipal solid waste in bioreactor landfills: predictive performance using coupled modeling
}

\author{
Kumar G. and Reddy K.R.* \\ University of Illinois at Chicago, Department of Civil \& Materials Engineering, 842 West Taylor Street, Chicago, IL 60607, USA \\ Received: 12/12/2018, Accepted: 14/04/2019, Available online: 17/04/2019 \\ *to whom all correspondence should be addressed: e-mail: kreddy@uic.edu \\ https://doi.org/10.30955/gnj.002985
}

\section{Abstract}

Municipal solid waste (MSW) landfills are one of the major and most preferred waste management options in the United States and many other countries across the globe. The waste in conventional MSW landfills undergoes very slow decomposition due to limited amount of moisture. In this regard, the bioreactor landfills have emerged as an effective waste management option, wherein leachate recirculation/injection is carried out to enhance the moisture levels within the waste thereby facilitating rapid waste decomposition and leading to early waste stabilization. However, in practice the performance of bioreactor landfills has remained inconclusive due to the lack of sound basis for effective design and operation of such landfills. This further stems from the fact that there is a limited understanding of the physical, chemical and biological processes and their coupled interactions on the MSW behavior in landfills. Hence, it becomes imperative to understand the influence of the coupled processes on the waste behavior to predict the overall performance of bioreactor landfills. Several researchers have developed numerical models to simulate waste behavior but only a few models have considered the simultaneous interactions of hydraulic, mechanical, and biological processes within the waste in their numerical model. In this study, newly developed numerical framework incorporating coupled thermo-hydro-bio-mechanical processes is presented. The numerical model can predict the spatial and temporal variation of waste temperatures, moisture distribution, gas generation, pore pressures, waste settlement, waste slope stability, and interface shear response in the landfill liner system. The numerical model has been validated with lab-scale and field-scale experiments and could be used to design and operate stable and effective bioreactor landfills.

Keywords: Solid waste management, bioreactor landfills, leachate recirculation, coupled processes, numerical modeling, composite liner system.

\section{Introduction}

Landfilling of municipal solid waste, although being the least preferred option, is the most dominant method of managing waste in U.S. and many other countries across the globe. In the light of steady increase in the population and rapid urbanization, the amount of waste produced is also increasing considerably. According to United States Environmental Protection Agency (USEPA), about 262 million tons of MSW was produced in 2015 of which nearly 138 million tons was landfilled (USEPA, 2018). The current practices for construction of traditional engineered landfills that just serve as waste containment systems are well established. This isolated system primarily contains the landfilled MSW in a relatively dry state and is designed with soil cover systems at the top of the landfill to prevent infiltration of water from the precipitation and with leachate collection and removal systems to remove any leachate accumulated over the bottom liner system. This results in a relatively dry condition within MSW causing slow decomposition of the organic matter (biodegradable constituents) within the waste due to the lack of adequate moisture. The slow decomposition of waste leads to several problems such as low gas generation rates, prolonged waste stabilization periods, increased post-closure monitoring requirements, increased leachate treatment and disposal costs, and a long-term liability of the land use with no beneficial purpose.

In recent years the idea of bioreactor landfills has gained wide attention because of its numerous benefits that can lead to sustainable waste management. A schematic of the operation of bioreactor landfill is shown in Figure 1. The bioreactor landfill uses the concept of an anaerobic digester, wherein the favorable conditions for rapid biodegradation of organic matter within the waste are maintained to accelerate the waste stabilization except that there is no rapid agitation as in the case of an anaerobic digester. In the field, these favorable conditions 
are achieved by recirculation of leachate and other permitted liquids along with addition of supplemental nutrients and/or inoculum of microbes, which results in adequate moisture levels and biochemical conditions suitable for rapid waste decomposition. Bioreactor landfills offer several benefits such as rapid waste decomposition, increased gas generation rates, high settlement rates and early waste stabilization. In addition, there are other secondary benefits such as reduced postclosure monitoring cost, reduced leachate treatment and disposal costs, and landfill space reclamation. Several laboratory studies and field-scale pilot tests have been performed confirming the enhanced decomposition of MSW with leachate recirculation into the waste mass. Although the leachate recirculation seems to be a viable concept, there are no established design practices for leachate recirculation, mainly due to the lack of adequate knowledge and data on the performance of such landfill systems. Unlike conventional landfills where leachate generation is limited, bioreactor landfills operate on intentional leachate/liquid recirculation/injection into the landfill, and if the leachate levels and pore pressures induced by the injection are not properly managed, it may cause instability in landfill resulting in landfill design failures.

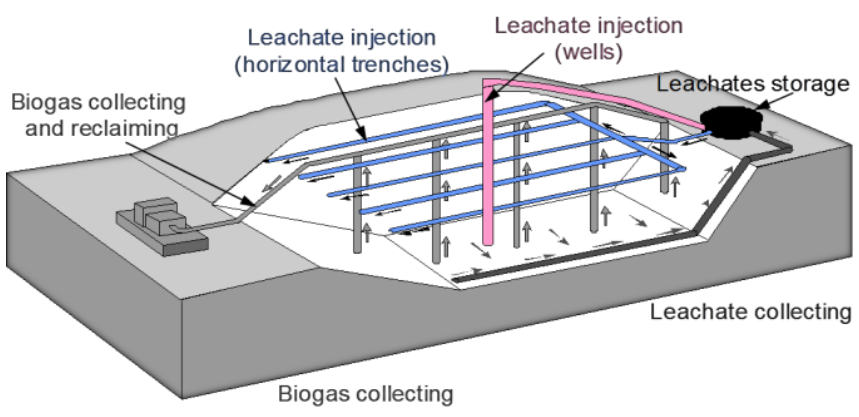

Figure 1. Schematic of a bioreactor landfill and its fundamental operations

In this regard, several numerical modeling efforts were carried out, to investigate the effectiveness of different leachate recirculation systems (LRS) in various configurations for uniformly distributing the injected leachate while maintaining the stability of landfill slopes under pressurized leachate injections (Kulkarni and Reddy, 2012; Reddy et al., 2017a). However, most of these studies neglected the effects of biodegradation and its consequent effects from settlement and gas generation on the fluid flow within the waste. The performance of a bioreactor landfill is influenced by several interdependent processes within the waste including the leachate flow and distribution, waste settlement due to the overburden stress and mass loss induced by waste decomposition, changes in the shear strength of the waste with degradation, and changes in temperature and heat generated from waste decomposition. Thus, there exists a complex system of simultaneously occurring and interrelated processes within the waste mass. There have also been several numerical investigations that looked at the coupled behavior of MSW accounting for the hydraulic, biochemical and mechanical behavior of MSW into a numerical model to simulate the coupled hydro-biomechanical response of MSW in landfills. But these models do not holistically assess the influence of the coupled processes on the performance of other engineered components of a landfill in terms of their stability and integrity within the landfill. In addition, most of the studies did not account for the heat generation and thermal behavior within the landfill and furthermore, if they did incorporate the effects of heat generation on the transient temperature distribution within the landfill, its influence on the biodegradation of waste was not accounted.

In this study a mathematical framework is formulated that can holistically assess the overall performance of the landfill by accounting for the interdependency of hydraulic (fluid flow and pore fluid pressure distribution), mechanical (stress and deformation, waste settlement and slope stability), biological (waste decomposition and gas generation) and thermal (heat generation and temperature distribution) processes within the MSW. A brief review of literature on the attempts to model MSW behavior in bioreactor landfills is presented and some of the major challenges associated with numerical modeling of MSW behavior in such landfills are presented.

\section{Coupled processes in MSW Landfills}

Municipal solid waste is a highly heterogeneous porous media with its properties (physical, mechanical and biological) varying spatially across the landfill due to inherent differences in waste composition. In addition, the rapid decomposition of the waste under leachate recirculation further exacerbates the situation by causing temporal changes in the waste properties. Thus, the overall performance of a bioreactor landfill is dictated by the combined effect of several interdependent system processes including hydraulic, mechanical, biochemical and thermal processes. A brief explanation of each of the system processes and their interactions with one another is explained in this section. A schematic of the major system processes and their interactions within the MSW landfills is shown in Figure 2.

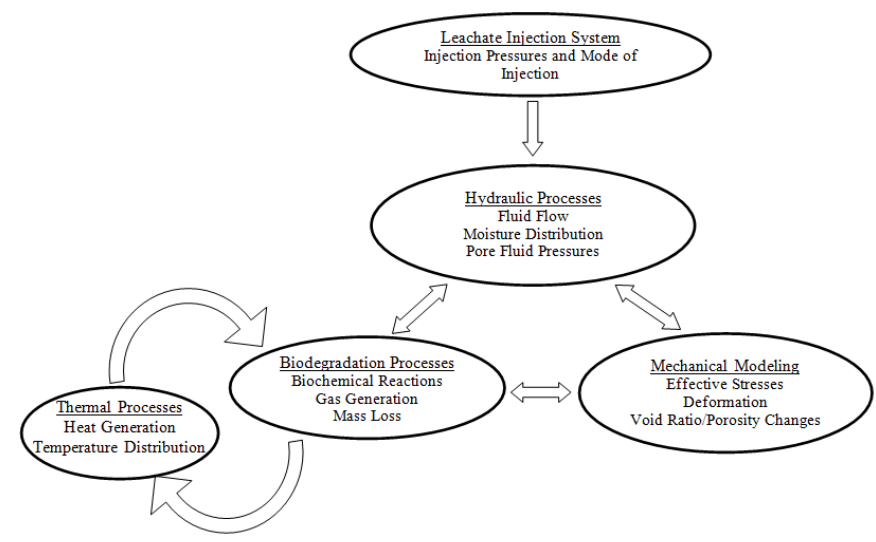

Figure 2. Major processes and their coupled interactions in msw landfills 
The hydraulic processes within the bioreactor landfills include the fluid flow (leachate flow) and the resulting distribution of moisture and pore-fluid pressures (liquid and gas phase). Due to the relatively low moisture in the MSW pore spaces, the fluid flow is generally and suitably assumed to follow unsaturated fluid flow behavior. Moreover, the decomposition of waste generates landfill gas (predominantly methane and carbon dioxide) leading to the gas flow and development of pore gas pressures within the MSW pore space that can have a great influence on the transient leachate flow and distribution. Thus, a two-phase flow behavior can be used to adequately simulate the fluid flow within the unsaturated waste mass.

The mechanical behavior of the waste is influenced by the overburden stress from the overlying waste layers and this differs spatially based on the landfill geometry and the spatially varying waste properties. The deformation and consequently the settlement of the waste is partly influenced by the mechanical properties of the waste (e.g. stiffness, strength parameters). However, the mechanical properties of the waste change temporally as the waste degrades and hence the change in the settlement of the waste induced by overburden stress. In addition to this, a significant amount of the waste settlement is borne out of the mass loss (conversion of biodegradable solids to landfill gas) resulting from the contemporaneous increase and decrease in void spaces within the waste due to waste degradation. This contributes to most of the waste settlement in MSW landfills.

The biochemical behavior of the waste is mainly dependent on the waste composition. Typically, most of the readily degradable matter is found to be cellulosic and hemi-cellulosic in nature and it contributes the most to the total methane gas production (Barlaz et al., 1990). Most of the biodegradation takes place anaerobically due to oxygen deprived conditions within the waste mass. The major biochemical reactions leading to the landfill gas production are hydrolysis involving the breakdown of higher molecular weight organic compounds to easily degradable monomers, followed by acid production (typically acetic acid) by microbially aided acidogenesis through fermentative bacteria, and finally the generation of methane by methanogenic bacteria. In all of this, the leachate chemistry and the biochemical reaction kinetics dictate the generation of landfill gas. Moreover, the biodegradation process is influenced by many factors including, temperature, $\mathrm{pH}$, and moisture among the most influential parameters.

The anaerobic biodegradation of organic matter in the MSW releases heat which influences the temperature within the waste mass. Furthermore, the resulting temperature in turn dictates the biodegradation of waste mass since the optimum degradation of waste by microbes occurs only at a certain temperature range. In addition, the spatial and temporal distribution of temperatures within the waste are influenced by the seasonal temperature changes as well. Thus, understanding the thermal behavior of MSW and incorporating its influence on the other system processes in a landfill plays a significant role in better prediction of the overall performance of the landfill.

Each of the above-mentioned processes occur and interact simultaneously within MSW, which influence the overall behavior of the landfill system. For example, the fluid flow (leachate and gas) within the MSW is dictated by the porosity, available moisture and the permeability of waste for the fluids. However, the decomposition of waste that occurs simultaneously as the fluid flows through the MSW causes the mass loss resulting in changes in the void spaces (porosity) and in turn influences the fluid flow thereafter. In addition, the increase in the void spaces can cause the waste to settle under the overburden stresses causing changes in the pore fluid pressures. Furthermore, the changing void space (void ratio) alters the moisture availability in MSW across the landfill, consequently influencing the rate of biodegradation MSW. The temperature dependent heat generation constantly influences the biodegradation of MSW and thereby the other processes impacted by the biodegradation of waste. It is quite evident that the landfill system is a unique and complex multiphase system with several processes occurring simultaneously in a coupled manner. It is of utmost importance to understand the individual system processes and their coupled interactions accurately to have a good prediction on the performance of a landfill system thereby enabling safe and effective construction and operation of bioreactor landfills.

\section{Previous investigations on bioreactor landfills}

Over the past few years a comprehensive research has been performed at the University of Illinois at Chicago (UIC) on bioreactor landfills involving field investigations, laboratory tests on MSW samples and numerical modeling of MSW behavior based on the characteristics of MSW as observed from the experimental studies. A list of all the previous studies on bioreactor landfills performed at UIC is shown in Table 1. A thorough field investigation was performed to determine the variation of in-situ moisture and density variation with depth and leachate injection were monitored to characterize the field waste. In addition, geophysical testing was performed to determine other dynamic and mechanical properties of waste. Several laboratory investigations were performed which involved testing of field MSW samples from a leachate recirculation landfill for their geotechnical properties such as the compressibility, shear strength, hydraulic conductivity, specific gravity, unit weight and other crucial properties. These properties were further evaluated at different stages of waste degradation to determine the effect of biodegradation on waste properties. In addition, biochemical testing was performed on the field MSW samples to determine the biochemical properties of MSW. All the tests performed on field MSW samples were also performed on synthetically prepared waste to have a control on the 
degradation and thereby evaluate the variation in waste properties with time.

Numerical modeling techniques are a great tool in simulating the coupled processes within MSW. It has been extensively used in order to understand the behavior of MSW and the influence it has on the performance of different components of a landfill. It is quite essential to assess the short-term and long-term integrity and stability of landfill components such as the liner and cover systems along with the stability of landfill slopes for a holistic assessment of the performance of a landfill system. In the recent years, a progressive modeling effort has been laid on trying to accurately simulate the different processes and their interactions in waste. Most of the initial numerical studies on bioreactor landfills performed in this regard neglected the combined effects of different processes and mainly focused on the hydraulic aspects of bioreactor landfills (e.g. moisture and pore pressure distribution). Some of the studies evaluated the effectiveness of different subsurface leachate recirculation systems (horizontal trenches, vertical injection wells, drainage blankets) in uniformly distributing the injected leachate (Kulkarni and Reddy, 2012; Reddy et al., 2013a,b; Reddy et al., 2014; Giri and Reddy, 2014a; Reddy et al., 2015b,c). Thereafter, the study was focused on evaluating the stability of landfill slopes under different injection pressures or flow rates (Giri and Reddy, 2014b,c; Giri and Reddy, 2015). Design recommendations were developed based on these investigations suggesting the safe injection pressures and setback distance for locating the injection system from the landfill slope that needs to be followed.

Table 1 Previous Research on Bioreactor Landfills at UIC

\begin{tabular}{|c|c|c|}
\hline Research Type & Topic of the Study & Reference \\
\hline \multirow{3}{*}{ Field Investigation } & In-situ properties of MSW at a leachate recirculating landfill & Grellier et al. $(2006,2007)$ \\
\hline & $\begin{array}{l}\text { Geophysical testing for evaluating dynamic properties of } \\
\text { MSW }\end{array}$ & Carpenter et al. $(2013 a, b)$ \\
\hline & $\begin{array}{l}\text { Field Monitoring and performance assessment of bioreactor } \\
\qquad \text { landfill }\end{array}$ & Reddy et al. (2009a) \\
\hline Laboratory Investigation & $\begin{array}{c}\text { Laboratory testing of geotechnical properties } \\
\text { (compressibility, shear strength, hydraulic conductivity, etc.) } \\
\text { of field and synthetic waste samples }\end{array}$ & $\begin{array}{c}\text { Reddy et al. (2009b,d,e); Reddy et al. } \\
\text { (2009b); Reddy et al. (2011); Reddy et } \\
\text { al. (2015a) }\end{array}$ \\
\hline \multirow{5}{*}{$\begin{array}{l}\text { Numerical } \\
\text { Modeling/Simulation }\end{array}$} & Settlement modeling & Babu et al. $(2010,2011)$ \\
\hline & $\begin{array}{c}\text { Modeling single phase (liquid) fluid flow in bioreactor } \\
\text { landfills to evaluate the moisture distribution by different } \\
\text { leachate injection systems }\end{array}$ & $\begin{array}{c}\text { Kulkarni and Reddy (2012); Reddy et } \\
\text { al. (2013a,b); Reddy et al. (2014); Giri } \\
\text { and Reddy (2014a); Reddy et al. } \\
(2015 b, c)\end{array}$ \\
\hline & Slope stability under pressurized leachate injection & $\begin{array}{l}\text { Giri and Reddy (2014b,c); Giri and } \\
\text { Reddy (2015) }\end{array}$ \\
\hline & Modeling of coupled hydro-mechanical processes & Giri and Reddy (2015d) \\
\hline & Modeling of coupled hydro-bio-mechanical processes & $\begin{array}{l}\text { Reddy et al. (2017a,b); Reddy et al. } \\
\qquad(2018 a, b)\end{array}$ \\
\hline
\end{tabular}

Recently, there have also been efforts to incorporate the coupled interactions between hydraulic, mechanical and biological processes into the numerical model to predict the MSW behavior in landfills (Reddy et al., 2017a). These studies focused on simulating the coupled hydrobio-mechanical processes to try and understand the complexity associated with the MSW behavior within the landfill and how it affects the holistic performance of a bioreactor landfill. In this regard a mathematical modeling framework that incorporates the coupled hydro-biomechanical processes and its impacts on the stability and integrity of the landfill system and its components has been formulated. In particular, this mathematical framework integrates a two-phase flow hydraulic model, a 2-D plane strain mechanical model, and a first order decay biodegradation model. The entire numerical framework is implemented in a software named FLAC which is based on a finite different numerical method.

The fluid flow is based on the Darcy's law while the hydraulic conductivity of the fluids under unsaturated conditions is given by the relative permeability functions of the van Genuchten form (van Genuchten, 1980).
The mechanical model for MSW involves the 2-D plane strain formulation of Mohr-Coulomb constitutive law to simulate the stress-strain behavior of MSW. The biodegradation of waste is simulated using the first order decay kinetics. The gas generation from waste degradation is similar to the USEPA's LandGEM model. However, the biodegradation model formulated in this study incorporates the effect of changing moisture as fluid flows through the MSW on the rate of biodegradation of waste. The extent of waste degradation at a location in the landfill is derived from the gas produced from the waste at that location over the biochemical methane potential of the waste. Meanwhile as the biodegradation takes place the waste properties also change as per the correlations developed between the extent of degradation and the geotechnical properties of the waste from previous experimental investigations on field MSW samples, thus simulating a transient coupled hydro-biomechanical behavior of MSW. A detailed explanation of the entire coupled hydro-bio-mechanical (CHBM) numerical framework and the numerical simulations performed on a typical landfill cell configuration (see 
Figure 3) using the CHBM numerical framework is presented in Reddy et al. (2017b). Some of the results obtained from these numerical simulations are presented here to demonstrate the predictive capacities of the numerical model.

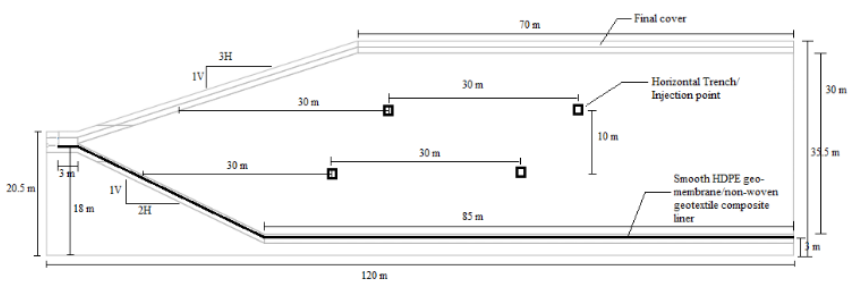

Figure 3. Schematic of the typical bioreactor landfill cell model used for the numerical analyses

\section{Results and discussion}

Figure 4 shows the evolution of the extent of moisture within the waste mass with time in terms of wetted area. In this study, wetted area is defined as the cross-sectional area of the waste in the 2D landfill model with a degree of saturation greater than $60 \%$. It is essentially a measure of the extent of moisture distributed across the landfill from leachate recirculation/injection. The value of $60 \%$ saturation is considered to be indicative of optimum moisture within the waste for enhanced waste decomposition (ITRC, 2006). It can be seen in Figure 4 that the wetted area increases with time due to leachate injection, but it is dictated by the fluid flow within the waste. The initial unsaturated state of the waste limits the rapid flow due to low relative permeability of the fluid in the initial stages. However, as the waste saturation increases so does the permeability of the fluid and thereby the extent of moisture distributed across the landfill also increases at a rapid rate. The landfill owners or the operators must be aware of the wetted area in the landfill to be able to estimate the moisture requirements and it is therefore an important operating parameter for bioreactor landfills which needs to be accurately predicted by a numerical model.

Figure 5 shows the evolution of cumulative volume of methane $\left(\mathrm{CH}_{4}\right)$ gas generated with time for the conventional (without leachate injection) and bioreactor landfill (with leachate injection) simulation. The results clearly indicate the distinct rates of $\mathrm{CH}_{4}$ gas generation between the two simulations indicative of the effect of moisture from leachate injection on the rapid decomposition of the waste in the bioreactor landfill simulation. It should be noted that the gas generation model is simplified to follow a first order decay kinetics which may not be an accurate way of estimating $\mathrm{CH}_{4}$ gas production. Several studies involving more realistic and rational approach towards exclusively for modeling of biodegradation waste have been published and efforts are underway to incorporate a biochemical reactions based model to simulate waste degradation and accurate prediction of $\mathrm{CH}_{4}$ gas generation.

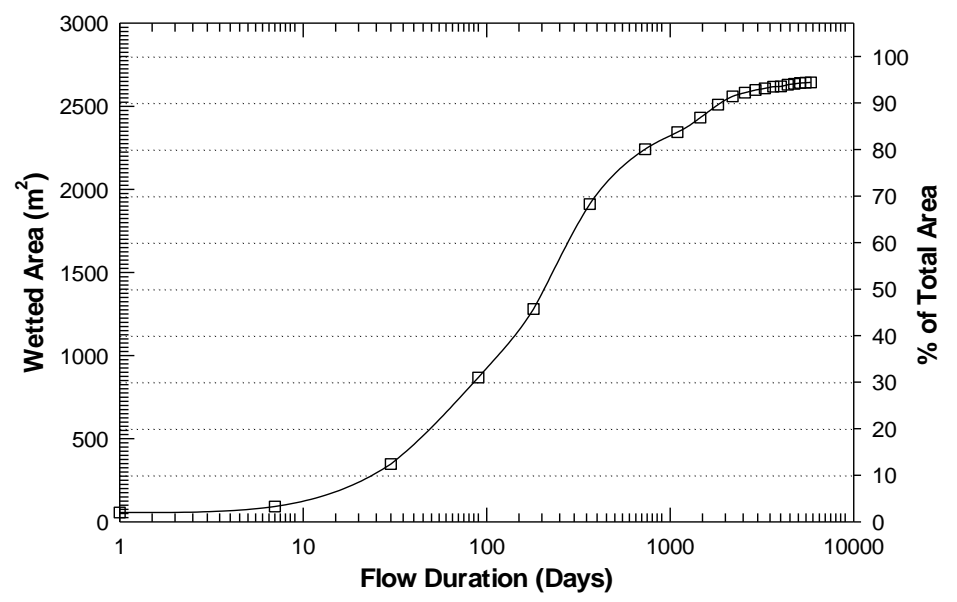

Figure 4. MSW wetted area with continuous periods of leachate injection at an injection pressure of $100 \mathrm{kPa}$ in bioreactor landfill

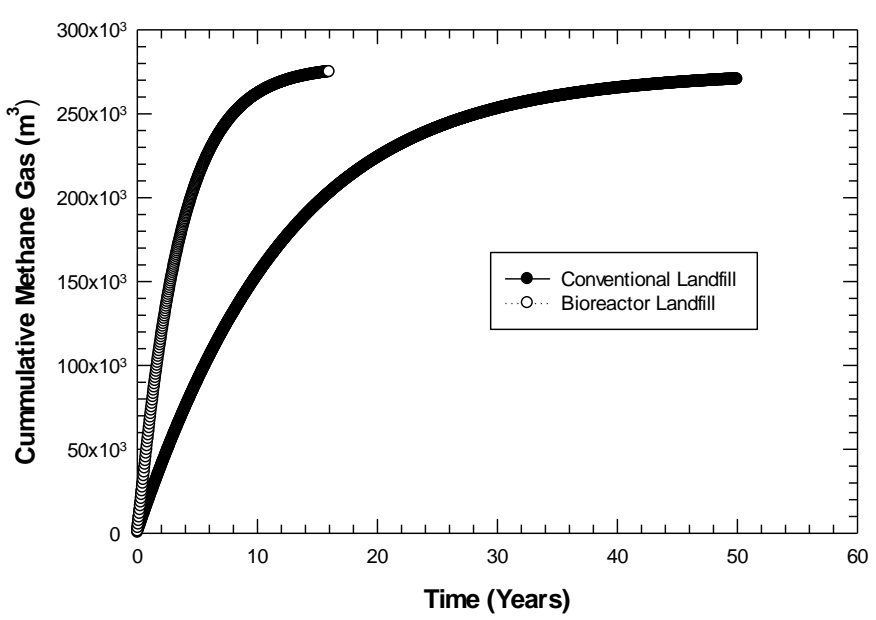

Figure 5. Cumulative methane gas generation for conventional and bioreactor landfill

Figure 6 shows the comparison of the variation of surface settlement with time for a conventional and bioreactor landfill. It can be observed that total settlement in both the cases is the same due to the same amount of waste and its composition in both conventional and bioreactor landfill simulation. However, the time it takes for attaining the total settlement in a bioreactor landfill is significantly less than the conventional landfill. This is mainly because of the higher rates of biodegradation in bioreactor landfill due to the availability of moisture from leachate injection and its distribution. The numerical model could simulate the different landfill settlement behavior with and without recirculation reasonably well. 


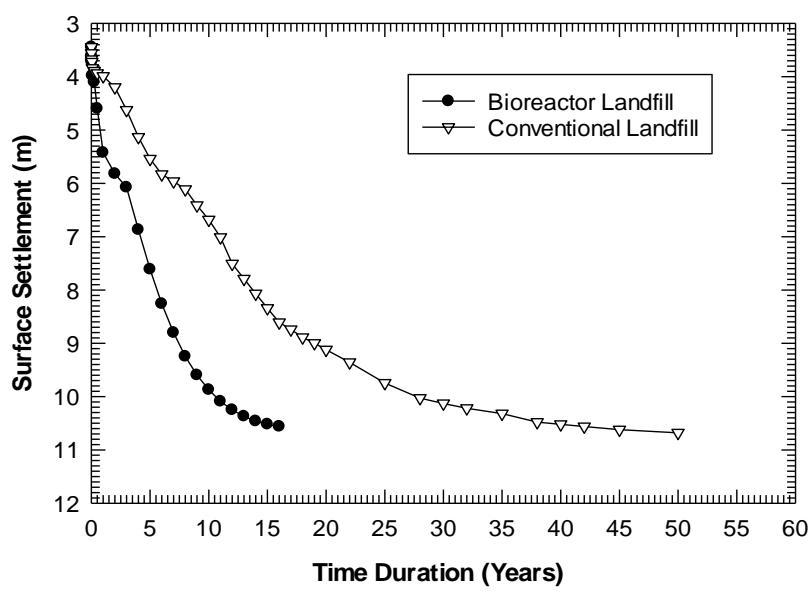

Figure 6. Variation of surface settlement in a simulated conventional and bioreactor landfill model

Figure 7 shows the results of slope stability in terms of factor of safety (FOS) for three numerical simulations of a landfill with the same waste conditions and landfill geometry. However, each of the three simulations incorporated different system processes. The first simulation represented a bioreactor landfill (involving leachate injection) but neglected the effect of biodegradation on the MSW behavior (coupled hydromechanical simulation). The second simulation represented a conventional landfill with no leachate injection (coupled bio-mechanical simulation) and the third simulation represented a bioreactor landfill with leachate injection (coupled hydro-bio-mechanical). The second and the third simulation incorporated the effect of biodegradation on MSW behavior. The three cases were evaluated for their slope stability under different simulated conditions. For the coupled hydro-mechanical simulation the factor of safety (FOS) against slope stability decreased continuously with increasing pore pressures from leachate injection (see Figure 7). For the coupled bio-mechanical simulation, there were no excess pore pressures as such in the system due to the absence of pressurized leachate injection. Thus, the FOS values almost remained constant over the entire simulation. However, for the coupled hydro-bio-mechanical simulation resulted in an initial decrease in the FOS values until certain time where the effect of increasing pore pressures was dominant. Meanwhile the changes in the waste properties (increasing unit weight, increasing cohesive strength of waste) resulted in an overall increase in the slope stability as indicated by the increase in FOS values. In the long-term with substantial settlement and dissipated pore water pressures and limited changes in the waste properties the FOS values decreased and reached a steady value. Hence, incorporating the effects of biodegradation along with other processes is essential for accurate prediction of the stability of a bioreactor landfill. However, the trend observed in Figure 7 should to be validated with actual field or other relevant experimental data to confirm such behavior.

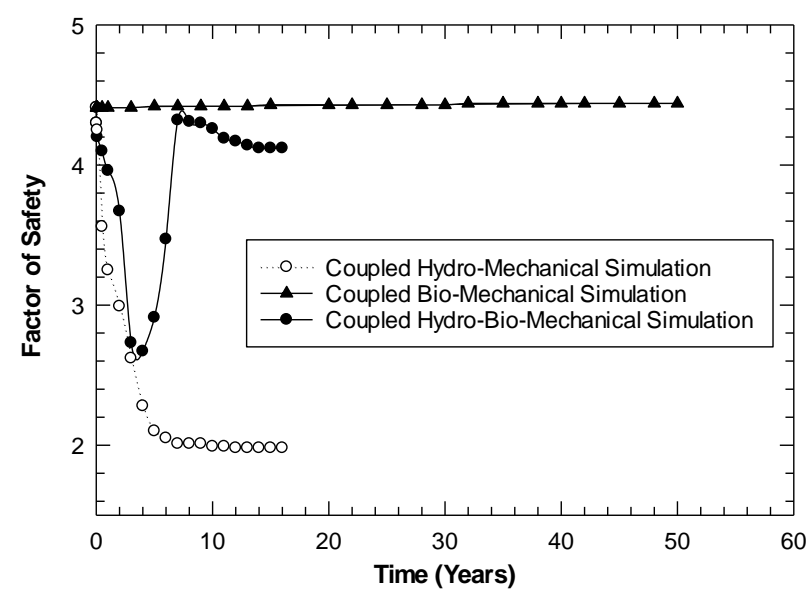

Figure 7. Variation of factor of safety of landfill slope with elapsed time for coupled hydro-mechanical, coupled biomechanical and coupled hydro-bio-mechanical simulation
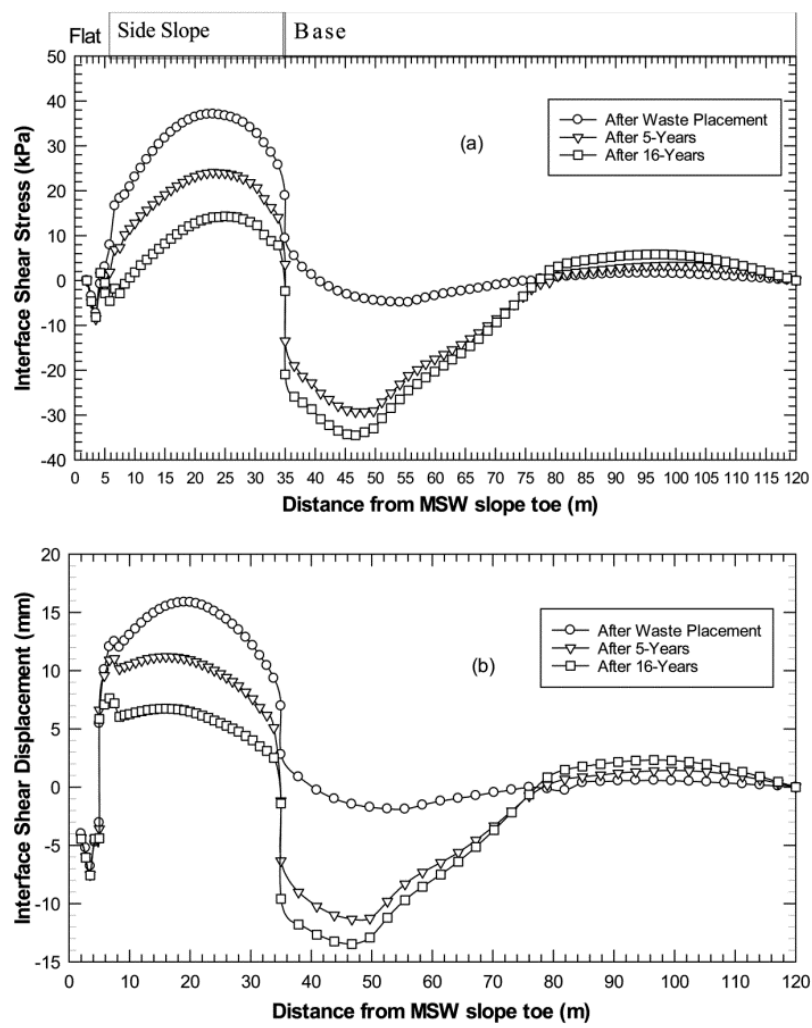

Figure 8. Evolution of (a) interface shear stress (b) interface shear displacement with elapsed time along the composite liner system for conventional and bioreactor landfill simulations

The unique ability of the CHBM numerical framework is to be able to capture the influence of coupled interactions within the waste on the waste-liner interaction. Modern landfills typically consist of composite liner system comprising of weak geosynthetic interfaces. The shortterm and long-term stability of the lining systems is mostly dictated by the shear behavior of weak geosynthetic interfaces under the influence of overlying waste. Figure 8 shows the shear response (shear stresses and shear displacements) of an interface formed by smooth 
High-Density Polyethylene (HDPE) geomembrane and nonwoven geotextile in a composite liner system for a bioreactor landfill simulation. Figure 8(a) and Figure 8(b) shows the induced shear stresses and shear displacements, respectively, along the flat run-out anchor, side slope, and base liner interface after the waste placement, after 5 years and after 16 years of leachate injection operation. The results show a characteristic trend in the distribution of the shear stresses and shear displacement along the interface. The shear stresses along the side liner increased, reached a peak value and decreased to zero, from left to right. Similarly, the shear stresses along the base liner from left to right increased, reached a peak value and then decreased to zero towards the right end of the base liner. This characteristic trend may be attributed to the boundary conditions imposed on to the landfill cell configuration (Reddy et al., 2017). Initially after the waste placement higher shear stresses and corresponding higher shear displacements were observed along the side slope liner owing to the mobilization of the friction between the geomembrane and geotextile interface. However, with time, the shear stresses along the interface were found to be influenced by the changing waste characteristics due to waste degradation and the shear stresses and shear displacements along the side slope liner decreased while the shear stress along the base liner increased with time. It is inferred that the changes in the waste stiffness (from being stiff at the early stages of degradation to being soft as the waste stabilizes) in the region around the side liner is found to have influenced the changes in the shear stresses and displacements along the side slope liner. In the lack of a conclusive evidence and explanation of such behavior there is a need for further study on the affect of changing waste characteristics on the shear response of the liner and consequently on the integrity of the liner. In this regard, the CHBM model expresses a great capacity in being able to associate waste behavior and the shear behavior of such interfaces in the liner system and predict the holistic performance of the bioreactor landfill and its components.

\section{Summary and ongoing research}

Bioreactor landfills are an attractive option for effective and efficient management of waste. They offer numerous advantages over the traditionally constructed and operated landfills in several aspects. Moreover, in the light of sustainable development, bioreactor landfills prove to be an ideal concept of waste management. However, there are no rigorous procedures or guidelines for safe and effective design of such landfills. Unlike conventional landfills, the construction and operation of bioreactor landfills require adequate knowledge and accuracy on the required moisture levels within the landfill, the injection pressures and flow rates all of which depends on a good estimation of the properties of waste. One of the major concerns in leachate recirculating landfills is to ensure uniform distribution of moisture across the landfill space, which is hindered by the lack of knowledge on the fluid flow in MSW. In addition, the biodegradation of MSW makes the understanding of the landfill system quite complex due to the interdependency of the hydraulic flow, mechanical response and biodegradation processes. Thus, understanding these individual processes and their interactions will aid in simulating this behavior mathematically thereby allowing us to design safe and effective bioreactor landfills.

Several researchers have performed numerous studies to numerically simulate the coupled processes. However, these studies do have some limitations from the simplification made in simulating the hydraulic, mechanical and biochemical processes. The current research at UIC is focused on addressing the research challenges pertaining to mathematical formulation of the biochemical reactions and their kinetics for realistic simulation of the biodegradation of MSW. More importantly, there are no coupled models that account for the influence of heat generation and temperature distribution within the landfill on the biodegradation of MSW and subsequently on the behavior of MSW and liner systems in landfills. Thus, numerical modeling of temperature distribution and heat generation within the landfill is currently being carried out to have an accurate description of the biodegradation of MSW (Kumar et al., 2018. In addition, accurate simulation of the mechanical response of the waste undergoing degradation is another complex topic that is being addressed. Understanding the mechanical behavior of waste has always been a challenging task and requires adequate experimental investigation to delineate and formulate the constitutive behavior that can simulate the waste behavior with reasonable accuracy. Finally, integration of all these different aspects into a comprehensive coupled model is crucial to predict overall performance of a bioreactor landfill.

\section{Acknowledgements}

This project is funded by the U.S. National Science Foundation (CMMI \# 1537514), which is gratefully acknowledged

\section{References}

Barlaz M.A., Ham R.K., Schaefer D.M. and Isaacson R. (1990), Methane production from municipal refuse: a review of enhancement techniques and microbial dynamics, Critical Reviews in Environmental Science and Technology, 19, 557584.

Carpenter P.J., Reddy K.R. and Thompson M.D. (2013a), Dynamic properties of municipal solid waste in a bioreactor cell at orchard hills landfill, Illinois, USA, 7th International Conference on Case Histories in Geotechnical Engineering, Wheeling, IL, USA

Carpenter P.J., Reddy K.R. and Thompson M.D. (2013b), Seismic imaging of a leachate recirculation landfill: Spatial changes in dynamic properties of municipal solid waste, Journal of Hazardous, Toxic, and Radioactive Waste, Vol. 17(4), 331-41

Giri R.K. and Reddy K.R. (2014a), Design charts for selecting minimum setback distance from side slope to horizontal trench system in bioreactor landfills, Geotechnical and Geological Engineering Journal, 32, 1017-1027

Giri R.K. and Reddy K.R. (2014b), Slope stability of bioreactor landfills during leachate injection: Effects of unsaturated 
hydraulic properties of municipal solid waste, International Journal of Geotechnical Engineering, 8, 144-156

Giri R.K. and Reddy K.R. (2014c), Slope stability of bioreactor landfills during leachate injection: Effects of heterogeneous and anisotropic municipal solid waste, Waste Management \& Research, 32, 186-197

Giri R.K. and Reddy K.R. (2015a) Slope stability of bioreactor landfills during leachate injection: Effects of geometric configurations of horizontal trench systems, Geomechanics and Geoengineering, 10, 126-138

Grellier S., Reddy K., Gangathulasi J., Adib R. and Peters C. (2006), Electrical resistivity tomography imaging of leachate recirculation in orchard hills landfill, SWANA Conference, Charlotte, 7p.

Grellier S., Reddy K.R., Gangathulasi J., Adib R. and Peters C. (2007), US MSW and its biodegradation in a bioreactor landfill, Sardinia 2007, 11th International Waste Management and Landfill Symposium, S. Margherita di Pula, Cagliari, Italy, p. 10

ITRC (2006). Characterization, design, construction and monitoring of bioreactor landfills. Washington: Alternative landfill technologies team, Interstate Technology and Regulatory Council.

Kulkarni H.S. and Reddy K.R. (2012), Moisture distribution in bioreactor landfills: A review, Indian Geotechnical Journal, 42, $125-149$

Reddy K.R., Gangathulasi J., Parakalla N., Bogner J., Carpenter P. and Lagier T. (2009a), Field monitoring and performance assessment of Orchard Hills bioreactor landfill, NSF Engineering Research and Innovation Conference, Honolulu, $\mathrm{HI}$, p. 13

Reddy K.R., Hettiarachchi H., Gangathulasi J., Parakalla N., Bogner J.E. and Lagier T. (2009b), Compressibility and shear strength of municipal solid waste under short-term leachate recirculation operations, Waste Management \& Research, 27, 578-587

Reddy K.R., Hettiarachchi H., Gangathulasi J., Bogner J.E. and Lagier T. (2009c), Geotechnical properties of synthetic municipal solid waste, International Journal of Geotechnical Engineering, 3, 429-438

Reddy K.R., Hettiarachchi H., Parakalla N., Gangathulasi J., Bogner J.E. and Lagier T. (2009d), Hydraulic conductivity of MSW in landfills, Journal of Environmental Engineering, 135, 677-683

Reddy K.R., Hettiarachchi H., Parakalla N.S., Gangathulasi J. and Bogner J.E. (2009e), Geotechnical properties of fresh municipal solid waste at Orchard Hills landfill, USA, Waste Management, 29, 952-959

Reddy K.R., Hettiarachchi H., Gangathulasi J. and Bogner J.E. (2011), Geotechnical properties of municipal solid waste at different phases of degradation, Waste Management, 31, 2275-2286

Reddy K.R., Hettiarachchi H., Giri R.K. and Gangathulasi J. (2015a), Effects of degradation on geotechnical properties of municipal solid waste from Orchard Hills Landfill, USA, International Journal of Geosynthetics and Ground Engineering, 1, 1-14

Reddy K.R., Kulkarni H.S. and Khire M.V. (2013a), Two-phase modeling of leachate recirculation using vertical wells in bioreactor landfills, Journal of Hazardous, Toxic and Radioactive Waste, 17, 272-284
Reddy K.R., Kulkarni H.S., Srivastava A. and Sivakumar Babu G.L. (2013b), Influence of spatial variation of hydraulic conductivity of municipal solid waste on performance of bioreactor landfills, Journal of Geotechnical and Geoenvironmental Engineering, 139, 1968-1972

Reddy K.R., Giri R.K. and Kulkarni H.S. (2014), Design of drainage blankets for leachate recirculation in bioreactor landfills using two-phase flow modeling, Computers and Geotechnics, 62, 77-89

Reddy K.R., Kulkarni H.S. and Giri R.K. (2015b), Design of horizontal trenches for leachate recirculation in bioreactor landfills using two-phase modeling, International Journal of Environment and Waste Management, 15, 347-376

Reddy K.R., Kulkarni H.S. and Giri R.K. (2015c), Design of vertical wells for leachate recirculation in bioreactor landfills using two-phase modeling, Journal of Solid Waste Technology and Management, 41, 203-218

Reddy K.R., Kulkarni H.S. and Giri R.K. (2015d), Modeling coupled hydro-mechanical behavior of landfilled waste in bioreactor landfills: Numerical formulation and validation, Journal of Hazardous, Toxic and Radioactive Waste, ASCE, 21, D4015004

Reddy K.R., Kumar G. and Giri R.K. (2017a), Modeling coupled processes in municipal solid waste landfills: An overview with key engineering challenges, International Journal of Geosynthetics and Ground Engineering, 3, 6

Reddy K.R., Kumar G. and Giri R.K. (2017b), Influence of dynamic coupled hydro-bio-mechanical processes on response of municipal solid waste and liner system in bioreactor landfills, Waste Management, 63, 143-160

Reddy K.R., Kumar G. and Giri R.K. (2018a), System effects on bioreactor landfill performance based on coupled hydro-biomechanical modeling, Journal of Hazardous, Toxic and Radioactive Waste, ASCE, 22, 04017024

Reddy K.R., Kumar G., Giri R.K. and Basha B.M. (2018b), Reliability assessment of bioreactor landfills using Monte Carlo simulation and coupled hydro-bio-mechanical model, Waste Management, 72, 329-338

Sivakumar Babu G.L., Reddy K.R., Chouskey S.K. and Kulkarni H.S. (2010), Prediction of long-term municipal solid waste landfill settlement using constitutive model, Practice Periodical of Hazardous, Toxic, and Radioactive Waste Management, 14, 139-150

Sivakumar Babu G.L., Reddy K.R. and Chouskey S.K. (2011), Parametric study of MSW landfill settlement model, Waste Management Journal, 31, 1222-1231

USEPA (2018), Advancing Sustainable Materials Management: 2015 Fact Sheet (https://www.epa.gov/facts-and-figuresabout-materials-waste-and-recycling/advancing-sustainablematerials-management), Accessed on December 10, 2018. 